\title{
Evaluation of the Influence of Anemometer Position around Railway Structures on Wind Observation Data
}

\author{
Keiji ARAKI \\ Senior Researcher, \\ Toshiaki IMAI \\ Laboratory Head, \\ Meteorological Disaster Prevention Laboratory, Disaster Prevention Technology Division \\ Katsuji TANEMOTO \\ Minoru SUZUKI \\ Senior Researcher, \\ Senior Researcher, \\ Vehicle Aerodynamics Laboratory, Environmental Engineering Division

\begin{abstract}
Anemometers for operation control are mostly installed close to railway structures. Railway structures might therefore influence anemometer wind velocity data readings. The authors investigated the influence on the wind velocity of the anemometer position around typical railway structures through wind-tunnel tests and field wind observations. In the case of single-track embankments with a height of $6.5 \mathrm{~m}$ from the ground surface, the increase in wind velocity on the leeward side was greater than on the windward side of railway structures, for heights up to $4 m$ above rail level, as the wind direction approaches a 90 degree angle to the longitudinal direction of the railway structure.
\end{abstract}

Keywords: anemometer for operation control, influence of railway structures, wind-tunnel tests, field wind observations

\section{Introduction}

To secure the safety of trains against strong winds, anemometers for operation control are arranged along sections of railway line. Train dispatchers issue orders such as suspension of operations or speed restriction when the wind speed detected by the anemometers exceeds the limits set for operational control. Although these anemometers are generally installed close to railway structures, no quantitative evaluation is made of railway structure influence on wind measurement readings. Furthermore, the Guidance for Wind Observation [1] compiled by the Railway Committee for Strong Wind Counter-measures Council does not include quantitative descriptions of railway structure influence on wind observation data. Nonetheless Imai et al. (1998) reported that depending on wind direction, railway bridges influenced the wind-velocity values measured by anemometers installed within their vicinity [2]. In order to ensure more rational orders are dispatched in case of strong winds it is necessary to quantitatively evaluate the impact of anemometer position in relation to railway structures on wind observation data readings, and then relocate the anemometers to the most appropriate position. This paper reports on results of various tests to determine the optimum location for installation of anemometers around railway structures, namely: wind-velocity properties around railway structures investigated in wind-tunnel tests and field wind observations, and resulting influences from changing the position of the anemometers around railway structures on wind observation data.

\section{Outline of the evaluation of railway structure influence on wind-velocity observation data}

The present research used field results and wind-tunnel tests to gain insight into the influence of railway structures on anemometer measurements depending on their position. Three typical types of railway structure were used in these investigations: single-track bridges, doubletrack viaducts and single-track embankment.

A total of six structural variations were studied for single-track bridges and double-track viaducts as shown in Fig. 1 and 2, namely: two girder heights $(1 \mathrm{~m}, 3.5 \mathrm{~m})$ and three different cross-sections (standard type, wide type, and narrow type). Only one variant was examined for the single-track embankment as shown in Fig.3 (height of $6.5 \mathrm{~m}$ from the ground surface). The cross-sectional shape of the single-track embankment model used in wind-tunnel tests was geometrically similar to the cross-section of the single-track embankment where field wind observations were made.

Wind-tunnel tests were first performed for each of the seven types of railway structure reduced to a one to 40 scale, and wind-velocity data was collected at various measurement points around these structures. This wind-velocity data was then compared with wind-velocity data measured at points unaffected by railway structures, namely at center height of the car-body on the windward side. The car-body center height $-2.5 \mathrm{~m}$ above rail level - was subsequently defined as the reference point for wind-velocity data unaffected by railway structures.

The wind-velocity data obtained in wind-tunnel tests was actually the mean wind-velocity per measurement period. In contrast, operation control in case of strong winds uses instantaneous wind-velocity data collected from the anemometers. It was therefore seen as neces- 
sary to collect instantaneous wind velocity in order to be able to evaluate the influence of railway structures on wind observation data. As such, field wind observations around a single-track embankment were made, and used to calculate the peak-factor $k$; this index can be applied to form the correlation between mean wind-velocity and the maximum instantaneous wind-velocity (the definition of the peak-factor $k$ is presented in section 4.2).

Mean wind velocity values and their standard deviation obtained in wind tunnel tests, for each of the various measurement points were then combined with the peak factor values obtained from field wind observations in order to estimate the maximum instantaneous wind velocity for each of the measurement points located around the seven types of railway structure and at the reference point. Subsequently, the instantaneous wind-velocity ratio $R i$, was obtained by dividing the maximum instantaneous wind-velocities obtained at each measurement point by the wind-velocity at the reference point, making it possible to quantify the influence on instantaneous windvelocity of an anemometer's position in relation to a railway structure. Figure 4 shows the calculation flowchart to obtain $R i$ at the measurement points around the singletrack bridges, double-track viaducts and the single-track embankment using wind-tunnel test measurements and the field wind observation data.

\section{Measurement of wind velocity around railway structures in wind-tunnel tests}

\subsection{Overview of the wind-tunnel test}

Wind velocity was measured around certain types of railway structure, single-track bridges, double-track viaducts and a single-track embankment in wind-tunnel tests using $1 / 40$ scale models. Table 1 shows the wind-tunnel test conditions and Fig.5 shows the wind velocity measurement points around each railway structure model. An X-type probe was employed the hot-wired anemometer probe, which can measure two-dimensional windvelocity (main airflow direction and vertical direction). However, in the wind tunnel test results discussed in the sections below, only the main airflow component is considered. A turbulent boundary layer model was used to reproduce the vertical profile of the wind-tunnel airflow reproducing the vertical profile of natural wind in open track sections, which are often exposed to wind. The power index for the wind-tunnel airflow vertical profile was 0.14 close to 0.15 , which represents a category II rural area surface roughness according to the Recommendations for Loads on Buildings [3] (hereafter, referred to as the power index 1/7). Figure 6 illustrates the vertical profiles of the mean wind-velocity ratio (mean wind-velocity at measurement points divided by mean wind-velocity of the main airflow component of the wind-tunnel airflow) and the turbulence intensity (the standard deviations of the mean wind-velocity at measurement points divided by the mean wind-velocity at measurement points) of the main airflow component, which reproduces the turbulent boundary layer with the power index of $1 / 7$, for a single-track bridge and double-track viaduct. The mean wind-velocity ratio and the turbulence intensity of the main airflow component as shown in Fig. 6 were obtained from a turn-table without railway structure models. The profile of the mean wind-velocity of the main airflow on the turn-table with-

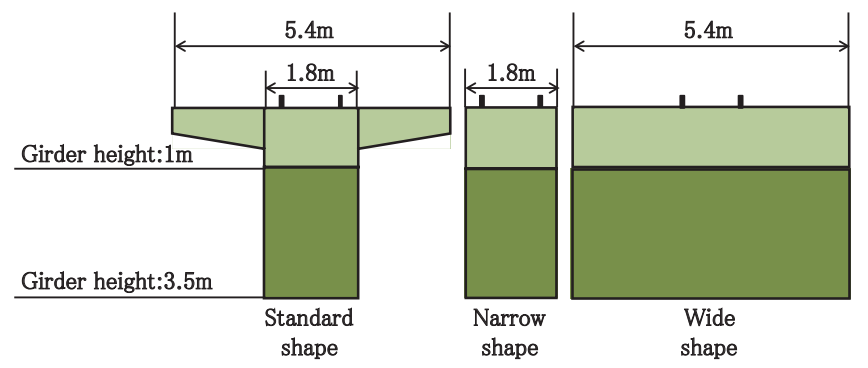

Fig. 1 Cross-sectional shapes of the single-track bridge used in wind-tunnel tests

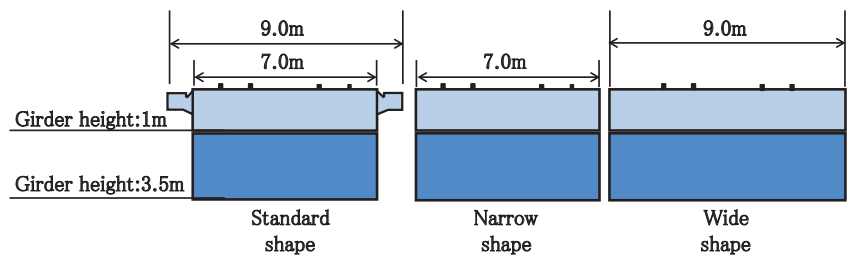

Fig. 2 Cross-sectional shapes of the double-track viaduct used for wind-tunnel tests

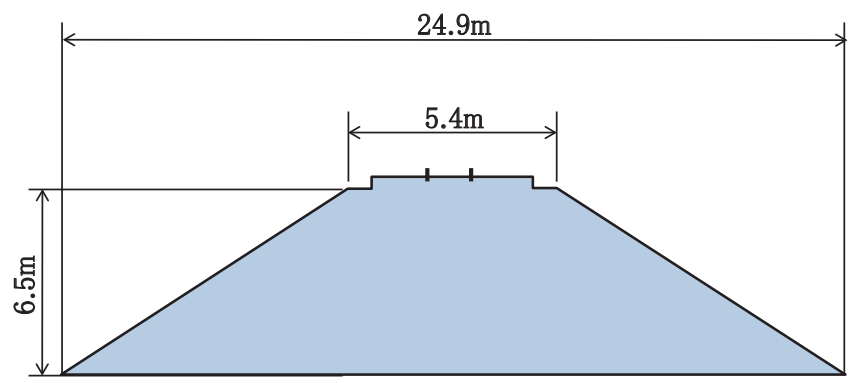

Fig. 3 Cross-sectional shape of the single-track embankment used in wind-tunnel tests

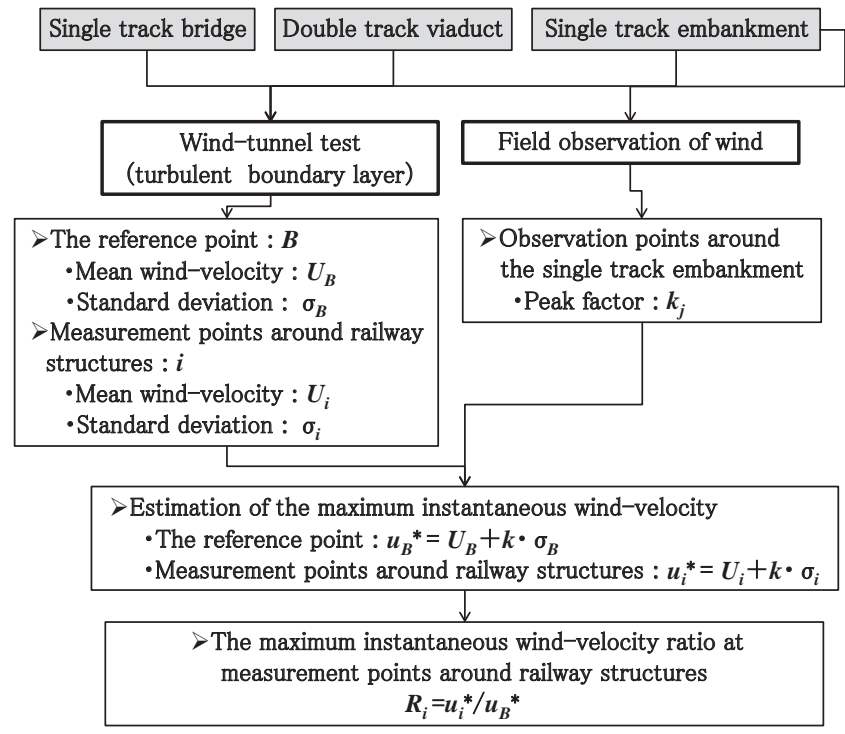

Fig. 4 Flowchart of calculation of the maximum instantaneous wind-velocity ratio $R i$ at measurement points around railway structures 
Table 1 List of wind-tunnel test conditions

\begin{tabular}{|c|c|c|c|}
\hline \multicolumn{2}{|c|}{ Railway structure } & $\begin{array}{l}\text { Single-track bridge } \\
\text { Double-track viaduct }\end{array}$ & Single-track embankment \\
\hline \multicolumn{2}{|c|}{ Wind-tunnel } & $\begin{array}{l}\text { IHI Inspection } \& \text { Instrumentation Co., Ltd. } \\
\text { Large-scale experimental wind tunnel } \\
(6 \mathrm{~m} \text { width } \times 3 \mathrm{~m} \text { height } \times 24 \mathrm{~m} \text { length })\end{array}$ & $\begin{array}{l}\text { Railway technical research institute } \\
\text { large-scale low-noise wind tunnel } \\
\text { (5m width } \times 3 \mathrm{~m} \text { height } \times 20 \mathrm{~m} \text { length) }\end{array}$ \\
\hline \multicolumn{2}{|c|}{ Hot-wire anemometer } & $\begin{array}{l}\text { KANOMAX Japan, Inc. IHW-100 } \\
\text { (probe }: 1241-20 \text { ) }\end{array}$ & $\begin{array}{l}\text { KANOMAX Japan, Inc. SYSTEM7000 } \\
\text { (probe }: 1241-20 \text { ) }\end{array}$ \\
\hline \multicolumn{2}{|c|}{ Model scale } & \multicolumn{2}{|c|}{$1 / 40$} \\
\hline \multirow{2}{*}{ 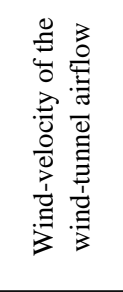 } & Setting & $8 \mathrm{~m} / \mathrm{s}$ & $20 \mathrm{~m} / \mathrm{s}$ \\
\hline & $\begin{array}{l}\text { Measured } \\
\quad U_{0}\end{array}$ & $\begin{array}{l}\text { Value of the wind-velocity measured by ultra- } \\
\text { sonic anemometer placed in the following } \\
\text { positions } \\
\text { - } 15.6 \mathrm{~m} \text { windward from turn-table center } \\
\text { - Horizontal center of the wind-tunnel } \\
\text { - Height of } 2.74 \mathrm{~m} \text { from the wind-tunnel floor }\end{array}$ & $\begin{array}{l}\text { Value of the wind-velocity measured by the } \\
\text { pitot tube placed in the following positions: } \\
\text { - } 5 \mathrm{~m} \text { windward from turn-table center } \\
\text { - } 1.5 \mathrm{~m} \text { away from horizontal center of the } \\
\text { wind-tunnel } \\
\text { - Height of } 1.84 \mathrm{~m} \text { from wind-tunnel floor }\end{array}$ \\
\hline \multirow{2}{*}{ 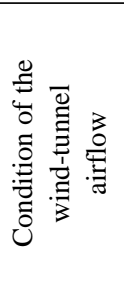 } & $\begin{array}{l}\text { Profile of } \\
\text { wind-tunnel } \\
\text { airflow }\end{array}$ & \multicolumn{2}{|c|}{$\begin{array}{l}\text { Turbulent boundary layer } U(Z) / U_{0}=\left(Z / Z_{0}\right)^{\alpha} \text {, power index } \alpha=1 / 7 \\
U(Z): \text { Mean wind-velocity of the wind-tunnel airflow at height } \mathrm{Z} \\
Z: \text { Height from the surface of the ground } \\
U_{0}: \text { Wind-velocity of the wind-tunnel airflow (measured value) } \\
Z_{0}: \text { Height of the turbulent boundary layer }\end{array}$} \\
\hline & $\begin{array}{l}\text { Turbulence } \\
\text { intensity }\end{array}$ & $\begin{array}{l}\text { Approximately } 15 \% \\
\text { (height of the rail level, } \\
\text { main-airflow- direction) }\end{array}$ & $\begin{array}{l}\text { Approximately } 17 \% \\
\text { (height of the rail level, } \\
\text { main-airflow-direction) }\end{array}$ \\
\hline \multicolumn{2}{|c|}{$\begin{array}{l}\text { Wind-direction } \\
\text { (azimuth of the railway } \\
\text { track was assumed to } \\
\text { be } 0 \text { degrees) }\end{array}$} & $\begin{array}{l}90 \text { degrees, } 67.5 \text { degrees, } \\
45 \text { degrees, } 22.5 \text { degrees }\end{array}$ & $\begin{array}{l}90 \text { degrees, } 70 \text { degrees, } \\
50 \text { degrees, } 30 \text { degrees }\end{array}$ \\
\hline \multicolumn{2}{|c|}{$\begin{array}{c}\text { Number of } \\
\text { measurement points }\end{array}$} & $\begin{array}{l}23 \text { (single-track bridge) } \\
27 \text { (double-track viaduct) }\end{array}$ & 16 \\
\hline \multicolumn{2}{|c|}{ Measurement item } & \multicolumn{2}{|c|}{ 2-dimensional wind-velocity (main airflow direction, vertical direction) } \\
\hline \multicolumn{2}{|c|}{ Record condition } & \multicolumn{2}{|c|}{$\begin{array}{c}1 \mathrm{kHz} \text { sampling frequency } \\
\text { Approximately } 40 \mathrm{sec} \text { sampling time per measurement point }\end{array}$} \\
\hline
\end{tabular}

out railway structure models was defined as the approaching wind.

Therefore, the mean wind-velocity $U_{B}$ at the reference point represents the approaching wind-velocity at a height of $2.5 \mathrm{~m}$ above rail level. The mean wind-velocity $U_{B}$ and turbulence intensity $\sigma_{B} / U_{B}$ in the case of the single-track bridge and the double-track viaduct were $6.6 \mathrm{~m} / \mathrm{s}$ and 0.14 respectively and $15.0 \mathrm{~m} / \mathrm{s}$ and 0.17 respectively in the case of the single-track embankment. The reference point for the wind-tunnel tests in this study was $2.5 \mathrm{~m}$ above rail level (or $20.2 \mathrm{~m}$ above the surface of the ground for the single-track bridge and the double-track viaduct, and $10 \mathrm{~m}$ above the surface of the ground for the single-track embankment). As shown in Table 1, the wind-tunnel conditions for the single-track bridge and the double-track viaduct differed from those for the single-track embankment wind-tunnel tests. A preliminary set of trials using the same railway structure models in both wind-tunnels however confirmed that there were no major differences in wind velocity readings between both types of wind tunnel.

\subsection{Wind-tunnel test results}

\subsubsection{Variation in mean wind-velocity ratio and turbulent intensity attributed to differences in the cross-sectional shape railway structures}

Existing bridges or viaducts vary in cross-sectional shape despite identical girder height. If the difference in cross-sectional shape of railway structures strongly influences the wind-velocity distribution around them, then wind-velocity distribution needs to be examined for each different railway structure cross-section.

It was therefore decided to examine wind-velocity distribution by wind-tunnel testing around single-track bridge and double-track viaduct with three different crosssections: standard, wide and narrow. Figure 7 shows the mean wind-velocity ratios and turbulence intensities for each cross-sectional shape in the case of double-track viaduct with a girder height of $3.5 \mathrm{~m}$ and wind-direction of 90 degrees. The mean wind-velocity ratio here corresponds to the mean wind-velocity at each measurement point $U i$ divided by the mean wind-velocity at the reference point $U_{B}$. The dotted line in Fig.7 shows the approaching windvelocity ratio, obtained by dividing the approaching wind- 

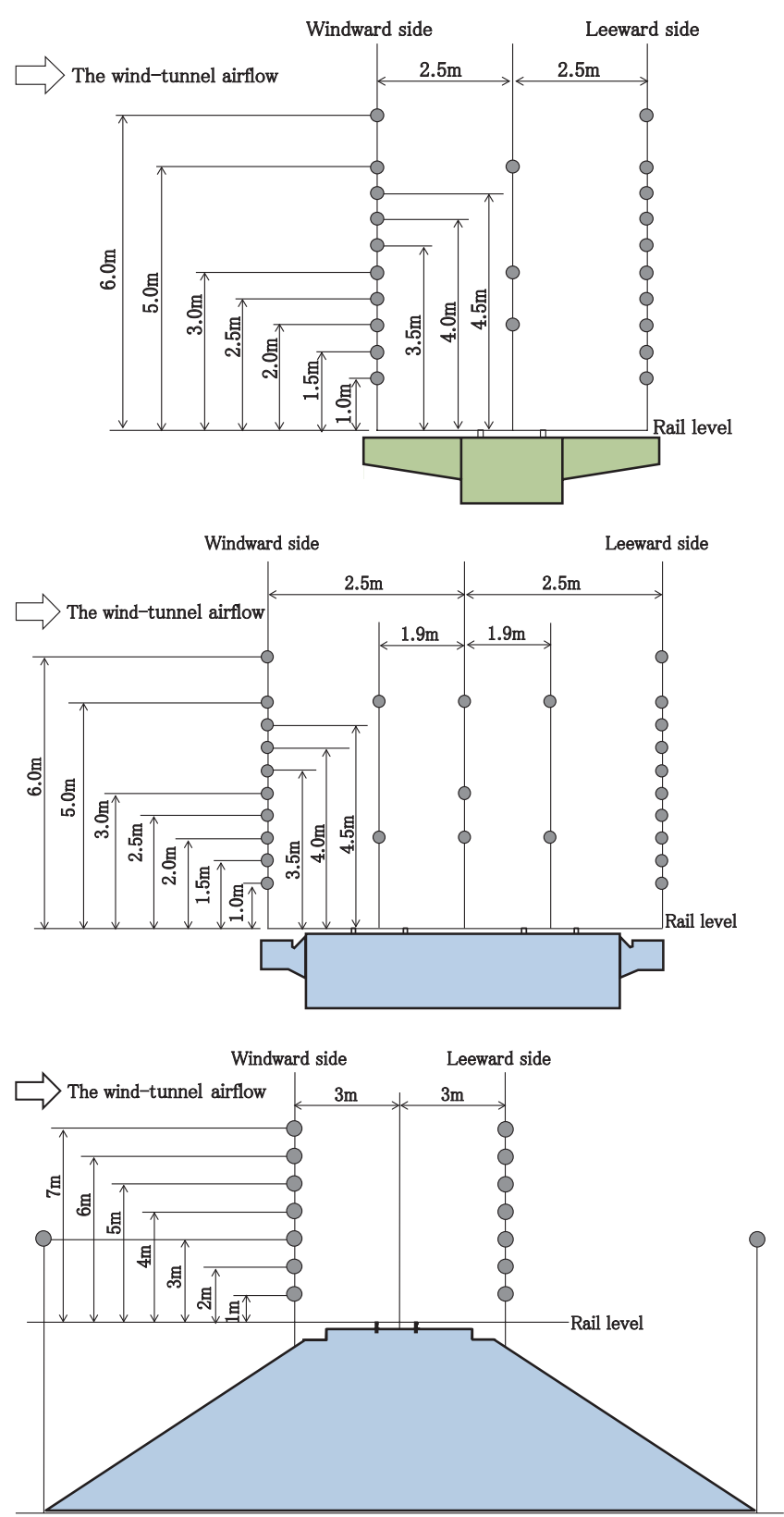

Fig. 5 Wind-velocity measurement points around railway structures in wind-tunnel tests (top: single-track bridge, middle: double-track viaduct, bottom: single-track embankment)

velocity by the mean wind-velocity at reference point $U_{B}$. As shown in Fig.6, the approaching wind velocity distribution in the wind-tunnel tests carried out for this study has a vertical profile. Since the approaching wind-velocity varies in the vertical direction, its velocity increases as it rises above the reference point and vice versa. As such, the mean wind-velocity ratio obtained by dividing the mean wind-velocity at a measurement point $U i$ by the mean wind-velocity at the reference point $U_{B}$, includes both wind-multiplication (or wind-deceleration) effect from the railway structure and vertical variation in approaching wind based on its vertical profile. Consequently, the windmultiplication (or wind-deceleration) effect caused by railway structures can be extracted by subtracting the wind-

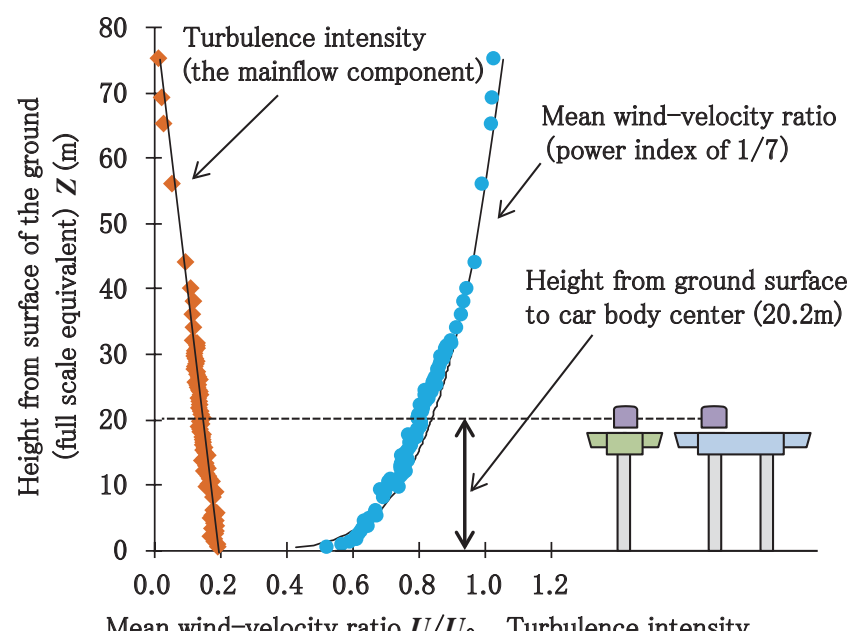

Fig. 6 Vertical profiles of the approaching wind (Examples of the single-track bridge and the double-track viaduct)
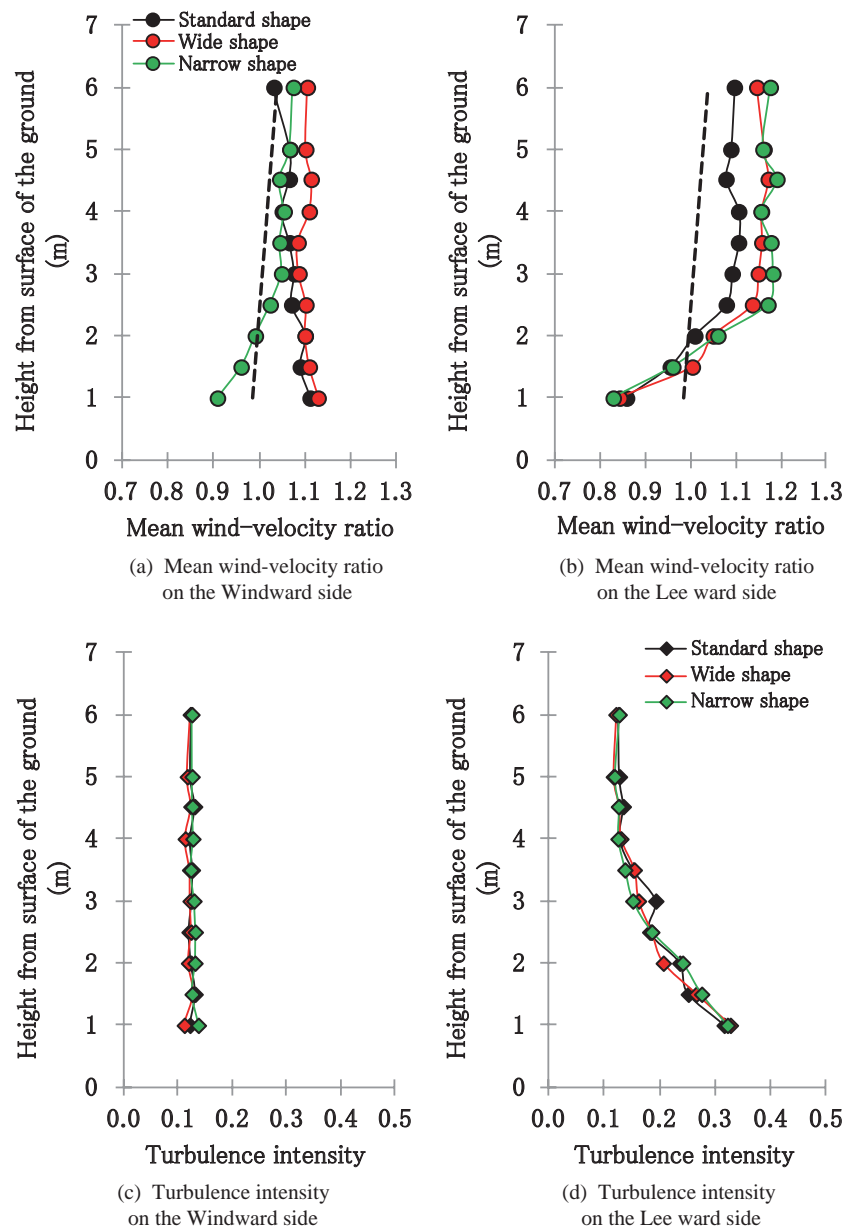

Fig. 7 Mean wind-velocity ratio and turbulence intensity according to cross-sectional shape (Example of the double-track viaduct with a girder height of $3.5 \mathrm{~m}$, wind-direction angle of 90 degrees)

velocity ratio of the approaching wind (dotted line in Fig.7 (a) and (b)) wind from mean wind-velocity ratios (black, red and green lines in Fig.7 (a) and (b)) at each measurement point. 
Hereafter, the mean wind-velocity ratio and the maximum instantaneous wind-velocity ratio refer only to the wind-multiplication (or wind-deceleration) effect due to railway structures obtained through above mentioned extraction process. Figure 7 (a) and (b) shows that variation in mean wind-velocity ratios for different cross-sectional shapes at measurement points on the windward side is greater than on the leeward side, with the most striking variations appearing at heights closer to the rail level. At measurement points $1 \mathrm{~m}$ above rail level on the windward side, the mean wind-velocity ratios for standard, wide and narrow cross-sections were 1.13, 1.14 and 0.92 respectively. The difference in wind-velocity ratio between the standard and wide cross section was $1 \%$, and was $21 \%$ between the standard and narrow cross section. At measurement points on the leeward side, the vertical difference in mean wind-velocity ratios between the standard and other two types of cross section ranged from 1 to $11 \%$.

Figure 7 (c) and (d) shows that variation in turbulence intensity for the different cross-sections was small. Turbulence intensity in the case of the standard cross section varied between $0.12-0.13$ on the windward side, and between $0.11-0.37$ on the leeward side. The maximum difference in turbulence intensity between the standard and wide cross sections was $2 \%$ vertically both on the windward and leeward sides. The maximum difference in turbulence intensity between the standard and narrow cross sections vertically was $2 \%$ on the windward side, and $9 \%$ on the leeward side.

Other wind-tunnel test results not shown in Figure 7 also demonstrated that the vertical profiles of the mean wind-velocity ratio for a standard cross section were similar to those for wide cross sections, regardless of variation in wind-direction and girder height. Based on the above-mentioned results, the wide cross sectional shape was selected for single-track bridges and double-track viaducts for calculation of the maximum wind-velocity ratios below.

As a result, for the purpose of examining the influence of railway structures on wind observation values for existing single-track bridges or double-track viaducts, even if they have different shaped cross-sections to those of the railway structures employed in this study, if the cross-sectional horizontal and vertical dimensions can be treated in the same way, it follows that the maximum instantaneous wind-velocity ratios calculated for a wide single-track bridge or double-track viaduct cross section can be adapted.

\subsubsection{Mean wind-velocity and turbulence intensity around railway structures measured in wind- tunnel tests}

Figure 8 gives the mean wind-velocity ratios and turbulence intensities according to wind-direction around a double-track viaduct with a girder height of $3.5 \mathrm{~m}$ measured in wind-tunnel tests. The mean wind-velocity ratio at measurement points on the windward side displays a tendency to increase the higher the angle of wind-direction; however mean wind-velocity ratio variation in the vertical direction for each wind-direction was small. Turbulence intensities at the measurement points on the windward side ranged between $0.10-0.15$ regardless of variation in wind-direction and height above rail level. The vertical profiles of the mean wind-velocity ratio on the leeward side differed for each wind-direction; at measurement points $2-\mathrm{m}$ or more above rail level, the mean wind-velocity ratio grew as the wind-direction angle increased. At measurement points $1.5 \mathrm{~m}$ above rail level, the mean wind-velocity ratios in the four wind directions were almost identical, and at measurement points $1.0 \mathrm{~m}$ above rail level, the mean wind-velocity ratios for winddirection angles of 90 and 67.5 degrees were lower than those for wind-direction angles of 45 and 22.5 degrees. Turbulence intensities at measurement points for heights of $2-\mathrm{m}$ or less above rail level on the leeward side varied greatly depending on wind-direction: the greater the winddirection angle, the larger the turbulence intensity.
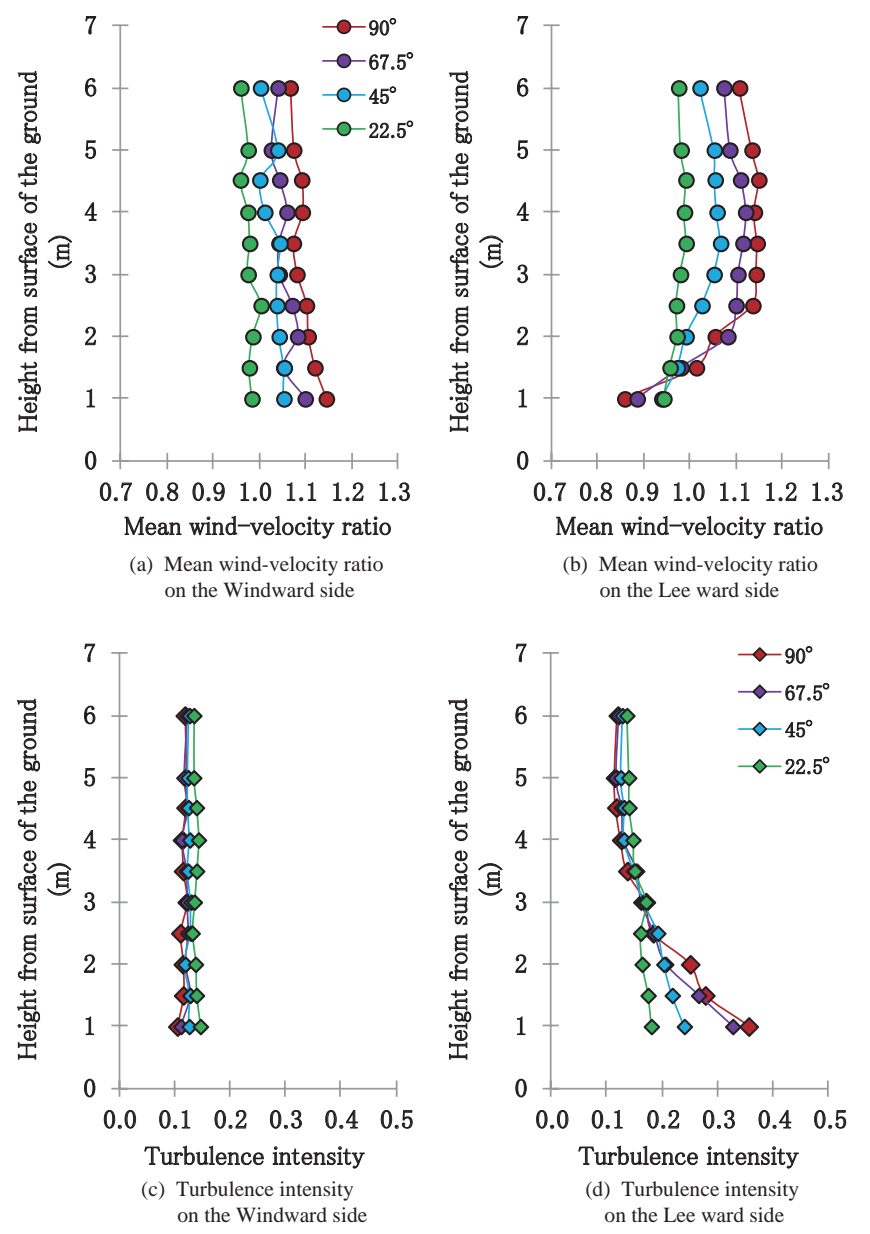

Fig. 8 Mean wind-velocity ratio and turbulence intensity according to wind-direction (Example of the wide double-track viaduct with a girder-height of $3.5 \mathrm{~m}$ ) 
4. Observation of wind-velocity and wind direction around a single-track embankment from field observation

\subsection{Overview of field wind observations}

Field observations were made of wind-velocity and wind direction around an actual single-track embankment in order to calculate the peak-factor, destined to be used for estimation of the instantaneous wind-velocity from the mean wind-velocity. Figure 9 shows the location of the observation points. Wind-velocity and wind direction measurements were made over a period of 380 days from February 14, 2009 to February 28, 2010. Three types of anemometers were employed: propeller-vane anemometers (CYG-5103, manufactured by R.M.YOUNG Co.), cup anemometers (02-2E, manufactured by Holy Co.) and ultrasonic anemometers (SAT-540, manufactured by Sonic Co.). Propeller-vane anemometers were placed in all observation points, whereas the cup and ultrasonic anemometers were situated at observation points B and C1. Nine anemometers were utilized overall (the cup anemometer can only measure wind-velocity, whereas the ultrasonic anemometer not only detects two-dimensional horizontal wind-velocity but also vertical wind-velocity). The sampling period for wind-velocity and wind direction field measurements was set at one second.

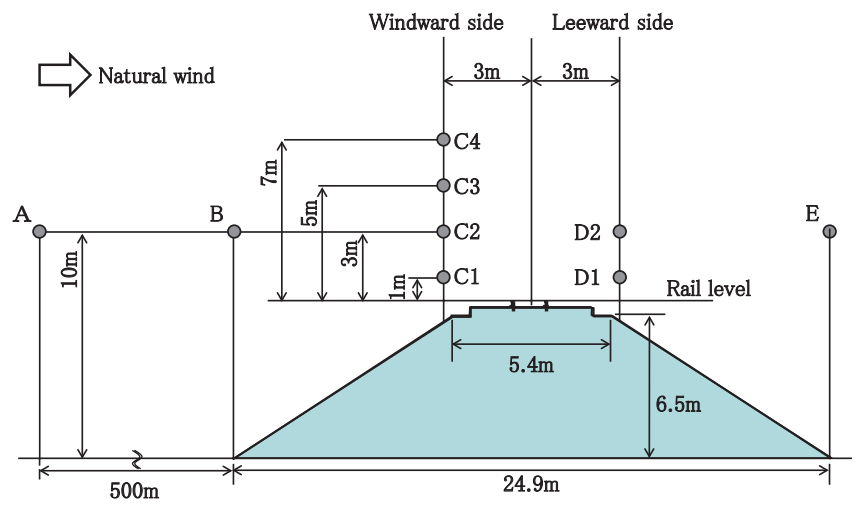

Fig. 9 Arrangement of wind observation points around the single-track embankment in field wind observations

\subsection{Peak factors calculated from field wind observation results}

The peak-factor $k_{j}$ was calculated for each of the nine observation points $j$ described above, from their wind-velocity data. The peak-factor $k_{j}$ is expressed by the following equation (1):

$$
k_{j}=\frac{v_{\max j}-V_{j}}{\sigma_{j}}
$$

Here, $v_{\operatorname{maxj}}$ means the maximum instantaneous wind-velocity at observation point $j, V_{j}$ means the mean windvelocity at observation point $j$ and $\sigma_{j}$ means the standard deviation of $V_{j}$.
Strong-wind data sets were extracted from the windvelocity and wind-direction measurements taken by the propeller-vane anemometers located in the nine observation points around the single-track embankment. Strongwind data sets were defined as sets of 1-minute representative wind data at nine observation points when the observed wind-velocity over 1-minute averaged at more than $10 \mathrm{~m} / \mathrm{s}$ at observation point B. Here, 1-minute representative wind data means 1-minute mean wind-velocity and wind-direction, 1-minute maximum instantaneous wind-velocity and wind-direction when 1-minute maximum instantaneous wind-velocity is observed, and standard deviation of wind-velocity. $k_{j}$ was calculated for each strong-wind data set by using equation (1). Figure 10 shows relative frequencies of $k_{j}$ at the nine observation points. Here, relative frequency of $k_{j}$ means the frequency of $k_{j}$ in each peak factor class divided by the total number of strong-wind data. The step size in each peak factor class set to 0.2 . The distribution of peak factor $k_{j}$ calculated by strong-wind data set displayed a mode value ranging between 2.0 to less than 2.2 regardless of observation point position. Confirmation was obtained that this result did not depend on the wind-direction in the strong-wind data set. Peak factor distribution calculated by using windvelocity data obtained with the cup anemometer and the ultrasonic anemometer also had a mode value ranging from 2.0 to less than 2.2. From these results, peak factor $k_{j}$ was considered as a constant $\mathrm{k}$, and utilized to calculate the maximum instantaneous wind-velocity ratio $R_{i}$ (the definition of the maximum instantaneous wind-velocity ratio $R_{i}$ is in the next chapter) by using $\mathrm{k}=2.0$.
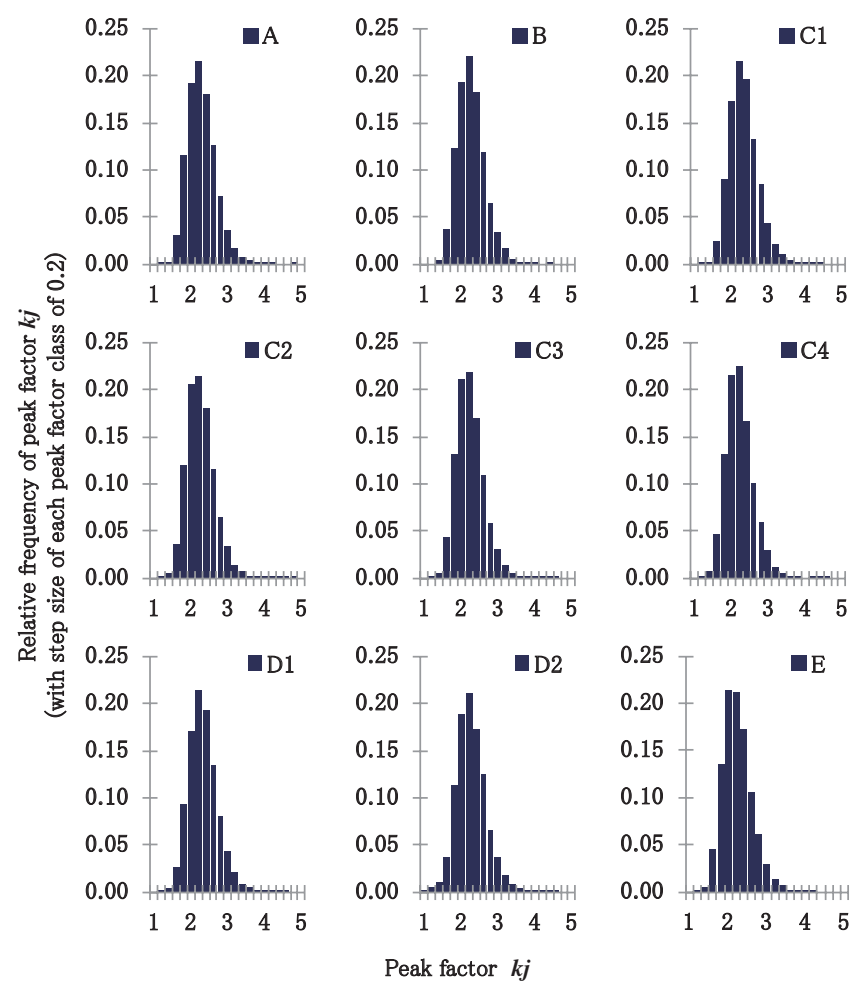

Fig. 10 Relative frequency of the peak factor at each wind observation point 
5. The maximum instantaneous wind-velocity ratio at measurement points around railway structures

The maximum instantaneous wind-velocities were calculated at measurement points $i$ around seven kinds of railway structure $\left(u_{i}^{*}\right)$ and at the reference point $\left(u_{B}^{*}\right)$ by equation (2) and (3)

$$
\begin{aligned}
& u_{i}^{*}=U_{i}+k \times \sigma_{i} \\
& u_{B}^{*}=U_{B}+k \times \sigma_{B} \\
& R_{i}=u_{i}^{*} / u_{B}^{*}
\end{aligned}
$$

Here, $U_{i}$ means 1-minute mean wind-velocity at measurement point $i$ around seven kinds of railway structure model obtained in wind-tunnel tests, and $\sigma_{i}$ means the standard deviation of $U_{i}$. The $U_{B}$ means 1 -minute mean wind-velocity at the reference point obtained in wind-tunnel tests, and $\sigma_{B}$ means the standard deviation of $U_{B}$. The constant $\mathrm{k}$ is the peak factor calculated from field observation results of wind around the existing single-track embankment and is equal to 2.0. The maximum instantaneous wind-velocity ratio $R_{i}$ was then found at measurement point $i$ around seven kinds of railway structure, by dividing $u_{i}^{*}$ by $u_{B}^{*}$. Figures 11,12 and 13 illustrate $R_{i}$ according to wind-direction at measurement point $i$ around three kinds of railway structure: single-track bridge with a girder height of $3.5 \mathrm{~m}$, double-track viaduct with a girder height of $3.5 \mathrm{~m}$ and single-track embankment with a height of $6.5 \mathrm{~m}$ from the ground surface. Regardless of the kind of the railway structure or measurement point on the windward or leeward side, these figures showed that maximum instantaneous wind-velocity ratio $R_{i}$ had a tendency to increase as wind direction angle rose, and as the height of the measurement point fell; this tendency was most striking in the case of measurement points on the leeward side. In contrast, regardless of the kind of railway structure and the measurement point on the windward side or the leeward side, the tendency was confirmed that the higher the height of the measurement point was, the smaller the wind-direction against to the railway track and the smaller the difference of the maximum instantaneous wind-velocity ratio $R_{i}$ would be. Where wind direction was 90 degrees, the maximum instantaneous wind speed ratio $R_{i}$ at measurement points on the leeward side ranged between 1.10-1.39 (single-track bridge), 1.08-1.23 (double-track viaduct) and 1.09-1.13 (single-track embankment) in the perpendicular direction. The degree of variation in the perpendicular direction of the maximum instantaneous wind-velocity ratio $R_{i}$ for the single-track bridge, double-track viaduct and single-track embankment were $29 \%, 15 \%$, and $9 \%$, respectively.

Compared with the maximum wind velocity at the reference point, a maximum instantaneous wind-velocity multiplication ratio of $20 \%$ or more was confirmed at measurement points for heights up to $3-\mathrm{m}$ above rail level (single-track bridge) and in for heights of between $1.5 \mathrm{~m}$ to $3 \mathrm{~m}$ above rail level (double-track viaduct). In addition, in the case of the single-track bridge, the maximum instantaneous wind-velocity multiplication ratio at measurement points for heights of between $1.5 \mathrm{~m}$ to $2.0 \mathrm{~m}$ above rail level reached $30 \%$. In the case of the single truck
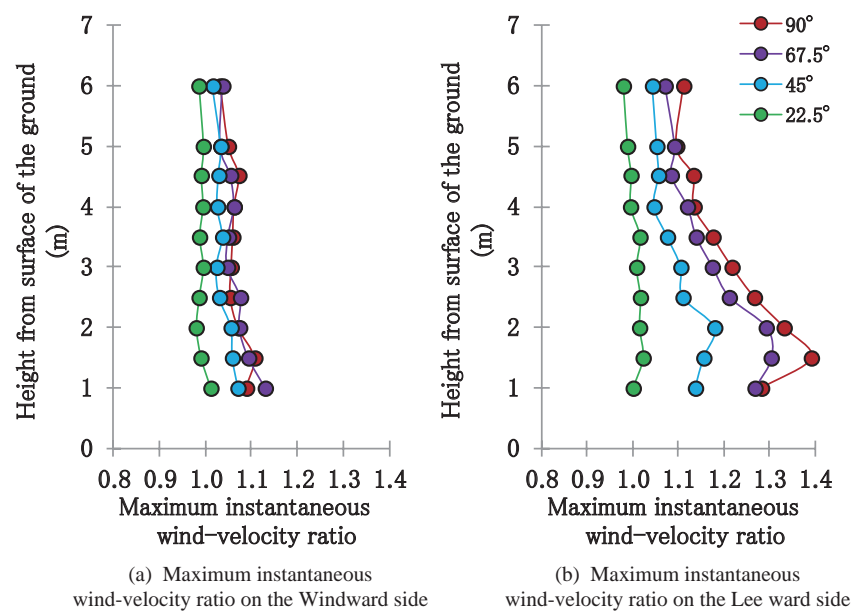

Fig. 11 Maximum instantaneous wind-velocity ratios at measurement points around the single-track bridge
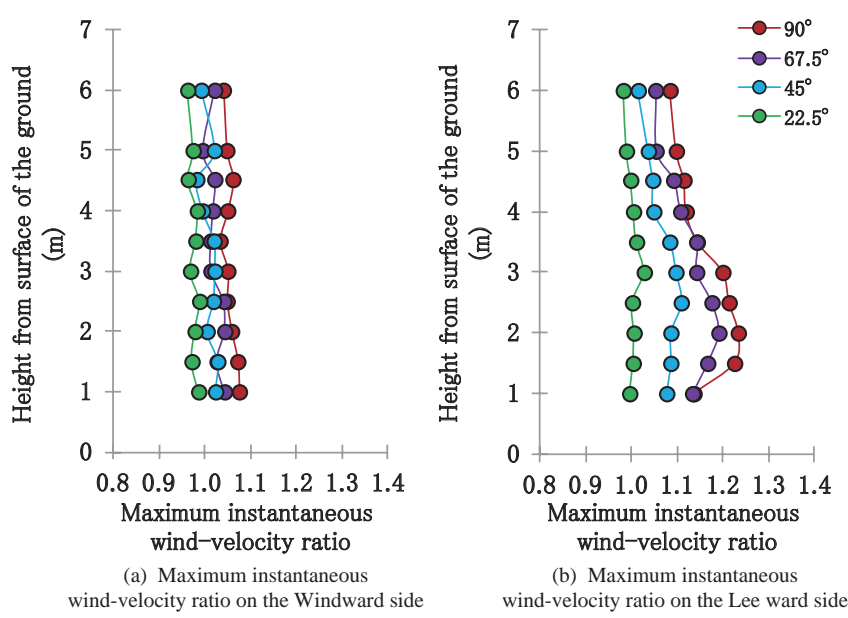

Fig. 12 Maximum instantaneous wind-velocity ratios at measurement points around the double-track viaduct
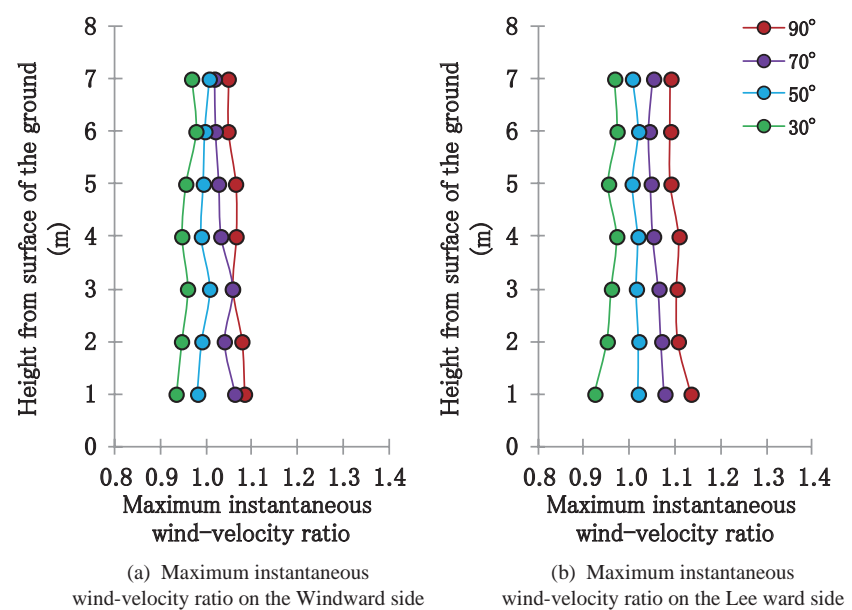

Fig. 13 Maximum instantaneous wind-velocity ratios at measurement points around the single-track embankment 
embankment, however, the maximum instantaneous wind-velocity multiplication ratios were less than $20 \%$ at every measurement point.

In comparison with the maximum instantaneous wind-velocity ratio $R_{i}$ at the measurement points on the leeward side those on the windward side showed a greater difference depending on wind-direction angle, and less variation in relation to height above rail level. Where wind direction was 90 degrees, the maximum instantaneous wind-velocity ratio $R_{i}$ at measurement points on the windward side was between 1.03-1.11 (single-track bridge), 1.03-1.08 (double-track viaduct) and 1.05-1.08 (singletrack embankment) in the perpendicular direction; every $R_{i}$ at measurement points on the windward side exceeded that of the reference point, however, the maximum instantaneous wind-velocity multiplication ratio of $10 \%$ or more was not confirmed, and variation in the maximum instantaneous wind-velocity ratio $R_{i}$ in the perpendicular direction was smaller than on the leeward side.

\section{Conclusions}

This study investigated the influence of anemometer position around railway structures on wind observation data by examining three types of railway structure (single-track bridge, double-track viaduct and single-track embankment), through wind-tunnel tests and field wind observations. The results are summarized as follows:

(1) Regardless of the kind of the railway structure, the maximum instantaneous wind-velocities at anemometer position on the leeward side of the railway structure were higher than those at the reference point (car-body center height on the windward side where the railway structure does not influence wind-velocity data) as the wind-direction against the railway track approached 90 degrees.

(2) Regardless of the kind of railway structure and measurement point on the windward side or leeward side, the maximum instantaneous wind-velocity ratio $\mathrm{Ri}$ showed a tendency where the higher the height of the measurement point was and the smaller the winddirection angle was in relation the railway truck was, the smaller the differences were among maximum instantaneous wind-velocity ratios $R_{i}$.

(3) In the case of the single-track bridge with a girder- height of $3.5 \mathrm{~m}$, the maximum instantaneous wind-velocities at anemometer positions on the leeward side for heights up to $3-\mathrm{m}$ above rail level were $30 \%$ or greater than those at the reference point with a winddirection angle of 90 degrees in relation to the railway track. In the case of the double-track viaduct with a girder height of $3.5 \mathrm{~m}$, the maximum instantaneous wind-velocities at anemometer positions on the leeward side for heights up to $3-\mathrm{m}$ above rail level were $20 \%$ or greater than those at the reference point with a wind-direction angle of 90 degrees in relation to the railway track.

(4) In the case of the single-track embankment with a height of $6.5 \mathrm{~m}$, the maximum instantaneous wind-velocities at anemometer positions on the leeward side for heights up to $4 \mathrm{~m}$ from the rail level were $10 \%$ or greater than those at the reference point with a winddirection angle of 90 degrees in relation to the railway track.

In this study, three structures were examined, but actual field wind observations were only carried out for the single-track embankment, and not for the single-track bridge and the double-track viaduct. To validate application of the peak factor obtained from field wind observation results on the single-track embankment in the estimation of the maximum instantaneous wind-velocity around single-track bridges and double-track viaducts, further research is planned to observe natural wind around these latter structures. Future work is also forecast to examine other embankment shapes and sizes in order to gather a broader set of results.

\section{References}

[1] Railway Strong Wind Measures Council, Guidance for Wind Observation, 2006 (in Japanese).

[2] Imai, T., Fujii, T., Tanemoto, K., Shimamura, T., Matsuda, Y., "An Observation of Partiality of Wind Speed on a Truss Bridge," Proceedings of The $5^{\text {th }}$ Jointed Railway Technology Symposium 1998, pp.639-642, 1998 (in Japanese).

[3] Architectural Institute of Japan, Recommendations for Loads on Buildings, Maruzen, 2004 (in Japanese). 